\section{Conferencing and Reporting: The Parent Connection}

\section{Joanne Graham and Alex Norrie}

W Fith renewed emphasis on accountability in education, teachers have been forced to revisit their understanding of assessment and evaluation to ensure their conceptions of teaching and learning are aligned with the assessment and evaluation practices that go along with them. As well, there has been an increased demand for more openness and scrutiny about the assessment and evaluation process by parents. Basic assumptions made are that:

- Parents have the right to know whatever the school knows about the abilities, the performance, and the strengths and weaknesses of their children.

- Parents must be informed of the educational outcomes of the program and how their child(ren) will be assessed on the various activities throughout the year.

- Schools must report the results in a form and manner that are comprehensible to parents.

Just as students need to understand the criteria used to judge their work, so too, do the parents of these students.

Most parents are genuinely interested in their child's achievement at school and in particular, how they can assist their child in improving. This is especially true for parents of elementary students and generally true for parents of secondary students.

The primary purpose for reporting to students and parents is to facilitate the students' learning and development. From a student's perspective this is done most effectively and efficiently on an ongoing, day-to-day basis within the context of the classroom. For parents this is usually communicated in a number of different ways, such as:

- report cards

- parent/teacher conferences

- letters from teachers,

- school newsletters

- telephone calls

- parent nights/workshops

- classroom visitations

- school council meetings and newsletters

- school and board websites

- and most recently e-mail.

Since parents do not usually have daily contact with schools, it is important for teachers to make parents aware of their respective programs in as many ways as possible. In addition, it is extremely important that the quality of the communication be very professional. As professional educators, we are privy to confidential information and we should be aware that all student records and dialogues with them and their parents must be kept private, confidential, and anonymous. In Ontario, we are governed by the Education Act and in particular Section 266 - Pupil Records. This section of the Education Act delineates how records should be kept and who has access to the Ontario School Records (OSR). The primary message is that all information is privileged and private, not to be shared with individuals not identified in the Act.

\section{Assessment Terms}

Before meeting with parents or guardians it is imperative that teachers have a clear understanding of some of the terms associated with assessment and evaluation. Nothing can embarrass a teacher more than not knowing the lexicon of assessment. This is especially true for the Education Quality and Accountability Office (EQAO) assessments administered to students in grades $3,6, \& 10$.

What then, is the difference between evaluation and assessment? Assessment is how we know we have delivered what we value. As such, it is the process of gathering information from a variety of sources to measure what students know and can do, and how well they can do it. Ongoing assessment should be integrated with instruction, should incorporate a variety of methods, and be used to help students learn and improve programs.

Evaluation on the other hand, is only one part of the assessment process. Evaluation takes place when teachers make judgments that recognize students' achievements and accomplishments in relation to activities and learning goals/expectations. The most recognized evaluation by parents is the report card. Further examination of the following terms serves to elaborate and make the difference between assessment and evaluation more lucid.

\section{- Authentic assessment:}

assessment strategies that explore and gather information about what students need to know and can do. Typically they enhance student learning as they require students to engage in activities that require problem solving or higher order thinking skills. Tasks are generally contextualized, time consuming and alternative scoring guides 
are necessary (Kirkwood, 2002; Martin-Kniep, 1992; Wiggins, 1989).

\section{- Diagnostic assessment:}

assessment methods utilized prior to and during teaching/learning. They provide the teacher with insight into students' existing knowledge, skills, and attitudes in relation to specific learning goals/expectations, and often identify program modifications needed for new and continued (CAPE / OAME / OMCA, 1999; Kirkwood, 2002; Martin-Kniep, 1992; Wiggins, 1989).

- Formative assessment:

assessment strategies that are incorporated throughout teaching/ learning. Information gathered provides data about students' progress in relation to learning goals/expectations addressed.

This form of assessment also provides teachers with information as to the effectiveness of instruction in relation to modifications needed to further student learning (CAPE / OAME / OMCA, 1999; Kirkwood, 2002; Martin-Kniep, 1992; Wiggins, 1989).

- Summative assessment:

assessment that takes place at the end of teaching/learning. Combined with other forms of assessment, it can be used to evaluate student growth and achievement, as well as inform instruction for the purpose of improving student learning (CAPE / OAME / OMCA, 1999; Kirkwood, 2002; Martin-Kniep, 1992; Wiggins, 1989).

\section{- Evaluation:}

is summative by nature and is the reporting of end results. It serves the purpose of recognizing student accomplishment and is used to evaluate programs in relation to the decisions and actions that need to be taken to further promote student learning and understanding (CAPE / OAME / OMCA, 1999; Kirkwood, 2002;
Martin-Kniep, 1992; Wiggins, 1989).

- EQAO assessment:

Ontario Ministry of Education's mandated standard assessments for all students in grades 3,6, and 10 administered for the purpose of accountability and addressing recommendations made for educational improvement province wide. These are evaluative by nature.

\section{Collecting and Recording the Information}

One of the first steps in organizing a parent-teacher conference is to develop a system of recording students' work, which reflects student learning over the course of an entire term/unit. This involves setting up a comprehensive record keeping system that will not only contain comments, marks, etc. but also examples of students' work. Incorporating authentic assessment techniques will involve recording student progress in a varied number of ways so that a comprehensive picture of students' knowledge, skills, understanding and attitudes can be shared with parents.

The following suggestions could assist teachers in establishing and maintaining an appropriate recording system:

- Make sure that both students and parents know what, how, and when activities will be assessed.

- Include information that is needed by the student or parent.

- Involve students in establishing the marking system. With authentic assessment parents could also play a role in creating recording and reporting system.

- Recording systems should be able to handle a number of different assessment activities, e.g., portfolios, investigations, writing, tests, self and peer assessments.
- Recording should be extremely informative yet efficient and practical - enough detail to be diagnostic and useful.

- Recording information should start at the beginning of the term, continue throughout the year, and be shared in formal parent/teacher conferences.

- Recording systems should contain teacher formative information such as anecdotal records, observation notes, as well as summative information on each student's performance.

\section{Reporting Information to}

\section{Parents}

With the new initiative implemented by the Ontario government to include parents as partners in education, the face-toface conference provides an opportunity to plan cooperatively educational experiences that can maximize the child's educational potential. The parent/ teacher conference supplements other communication (report cards, letters, phone calls, classroom visits etc.) that the teacher has supplied to parents.

Conferences like all other components of education are most successful and productive when they are preceded by careful planning and conducted in a warm, friendly, professional manner.

The following section contains some suggestions that teachers may want to incorporate in their respective parent/teacher conferences:

\section{Organizing the conference}

- Think about what you want to say to the parents - know the purpose of the conference.

- Gather examples of students' work. Put them in order from the beginning of the term to the end. This will allow you to demonstrate educational growth or pin- 
point areas that need to be reinforced.

- Prepare some briefing notes based on samples of the student's work and your assessments. This will reveal to the parents that you have given the interview serious thought and that you view the task as important. Try to anticipate questions that the parents could ask and outline appropriate responses.

- If the conference follows a reporting period, rationalise in a common-sense manner final grades on the report card. This is especially true when explaining how classroom assessments are aligned with the various levels used by the Ontario education system.

\section{Setting the climate}

- Make sure your classroom is inviting comfortable and tidy. Insist that there be no interruptions during the parent/teacher conferences.

- Set up a table and chairs where parents can sit comfortably and discuss their child's progress with you.

- Be a listener not a talker. Do not dominate the interview. You may intimidate your parents and that defeats the purpose of the interview. Don't argue with your parents. Encourage parents to participate emphasizing the idea of partnerships.

- Be positive. Always start with describing the student's strong points. Find ways to accentuate the positive and deal with the negative in a constructive manner.

- Be honest and sincere.

- Stick to your time limits - explain to parents that they have $15 \mathrm{~min}$ utes for the conference. If more time is required, schedule another conference. Making parents wait because you have run over time limits could antagonize them.

\section{After the conference}

- Summarize the results of the conference to the parents. Make sure they agree with what has transpired during the interview.

- Invite the parents to make suggestions for improving their child's progress at school.

- Make recommendations to the parents that will incorporate their suggestions into a plan of action.

- Review the recommendations a final time with the parents.

- Thank the parents for coming to the conference and tell them you are looking forward to working with them over the course of the year.

- Make a plan to follow up in the immediate future and put it in writing so that you have a written record of the parent/teacher conference.

\section{Conclusion}

Assessing for student learning is an ongoing and integral part of the teaching/learning process.

Evaluating student learning is one, albeit important, part of assessment. While parents are interested in all aspects of their child's assessment, the parent-teacher conference and term report cards are most often the yardstick by which parents determine how well their child(ren) are doing. For this reason it is important for teachers to gather from many sources what each student knows and can do. Formal and informal records of students' achievement gathered and recorded on an ongoing basis, provides the teacher with a clear picture of each students' progress. When these records are aligned with reporting levels used by education systems and shared with parents, they provide parents with a comprehensive picture of their child(ren)s' achievement. The end result are informed parents who know the abilities, perfor- mance, and strengths and weaknesses of their children, based on the ongoing activities and learning taking place in the classroom, and the reported results that appear on the report card or EQAO assessments.

\section{References}

Coordinators/Consultants' Association for Primary Education (CAPE), Ontario Association of Primary Educators (OAME) \& Ontario Mathematics Coordinators' Association (OMCA). (1999). Linking Assessment \& Instruction in Mathematics: The Primary Years. Ontario: OAME

Kirkwood, K.J. (2002). Assessment for the classroom teacher. Brock University, St. Catharines, Ontario.

Martin-Kniep, G. (1992). Authentic assessment in practice. Adelphi University, Garden City, New York.

Wiggins, G. (1989). A true test: Toward more authentic and equitable assessment. Phi Delta Kappan, 70, 703-713.

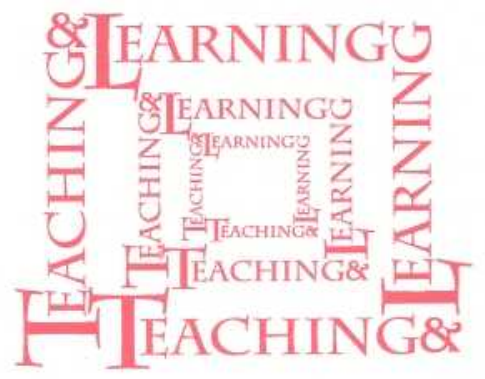

\section{Quotable Quotes}

I believe that imagination is stronger than knowledge.

That myth is more potent than history.

That dreams are more powerful than facts.

That hopes always triumph over experience.

That laughter is the only cure for grief.

And I believe that love is stronger than death.

Veronica Lacey 